\title{
Role of Modern Technologies in Tissue Engineering
}

\author{
Qurban Ali $^{1,}{ }^{*}$, Sabeen Malik ${ }^{1}$, Arif Malik ${ }^{1}$, Muhammad Nadeem Hafeez ${ }^{2}$ and Said Salman ${ }^{3}$ \\ ${ }^{1}$ Institute of Molecular Biology and Biotechnology, University of Lahore, Lahore, Pakistan \\ ${ }^{2}$ Department of Pharmacy, University of Chieti-Pescara “G. d'Annunzio", Chieti, Italy \\ ${ }^{3}$ Department of Plant Breeding and Genetics, Gomal University, Dera Ismail Khan, Pakistan \\ "Corresponding author: Institute of Molecular Biology and Biotechnology, University of Lahore, Lahore, Pakistan. Email: saim1692@gmail.com
}

Received 2019 February 06; Revised 2019 October 15; Accepted 2019 December 18.

\begin{abstract}
Nanotechnology is a rapidly developing field with numerous applications spread in different fields, especially medicine. It plays a role in tissue engineering, tissue regeneration, drug delivery, and regenerative medicine. The present brief review summarizes the role of nanotechnology in tissue engineering and tissue regeneration. The CRISPR/Cas9 system in tissue engineering is playing an important role, as CRISPR is a revolutionary genome-editing technology that is being used for tissue engineering where it emphasizes to address tissue architecture formation, immune response circumvention, cell differentiation, and disease model development. Moreover, the development and research expenses for tissue engineering and regenerative medicine are too high and there is a need for making these systems cost-effective. Thus, the advanced approach of applications of nanotechnology to regenerative medicine and CRISPR will definitely revolutionize the basis of treatment, prevention, and diagnosis of various diseases.
\end{abstract}

Keywords: Nanotechnology, Nanoparticles, Bio-Scaffolds, Tissue Engineering, Tissue Regeneration, Regenerative Medicine, CRISPR/Cas9 System

\section{Introduction to Nanotechnology and Nanoparticles}

Nanotechnology is a technology that deals with very tiny sized nanometer objects. It includes structures that fall approximately in the 1 to $100 \mathrm{~nm}$ size $\left(1 \mathrm{~nm}=10^{-9} \mathrm{~m}\right)$ at a minimum in one dimension. To understand this size range, the thicknesses of human hair, a bacterium, a virus, and a tiny molecule are about 100,000 nm, 1,000 nm, 100 $\mathrm{nm}$, and $1 \mathrm{~nm}$, respectively. Thus, nanotechnology particularly includes those objects that are up to many hundred nanometers in size $(1,2)$.

Nanoparticles (NPs) not only exist in nature but also are made as a result of human activity. These nano-sized materials possess a large surface area to volume ratio and their physiochemical properties like interaction with other molecules and friction are distinctive from those of similar objects of large size (3). Nanoparticles are complex molecules composed of three layers: (1) the top or surface layer, which is mostly functionalized with a variety of polymers, metal ions, surfactants, and small molecules, (2) a shell layer that differs from the core material chemically in all aspects and, (3) the core that is the main central part of NPs and mostly is referred to as nanoparticle itself (4). Due to their nano-sizes, they have fundamental material properties with many practical applications in numerous different areas, e.g., engineering, environmental remedi- ation, and medicine. Nanotechnology is a vast interdisciplinary field that utilizes knowledge from different domains of chemistry, biology, physics, health science, engineering, and material science. It has tremendous applications in nearly every discipline of human life and science.

Nanoparticles are solid particles or particulate dispersions with a size of 10 to 1,000 nm (5). Nanotechnology applications have spread into numerous fields since the last decade, such as biomedical engineering, medicine, and material science. The basis of this new technology lies in the formation and utilization of materials, devices, and surfaces at the molecular level. Nanotechnology has a significant role to play in the field of medicine where it is utilized for tissue engineering, diagnosis, and drug delivery (6). In the discipline of medical science, nanotechnology has been widely used for imaging modalities and development of novel therapeutics and it has the potential to revolutionize the present state-of-art in these fields. The National Cancer Institute in 2004 defined opportunities in six major areas, as follows: (1) drug delivery and therapy, (2) vehicles to assess in vivo efficacy of a therapeutic drug, (3) disease diagnosis and imaging, (4) a system with combined diagnostic and therapeutic applications, (5) detection of molecular changes responsible for disease pathogenesis and, (6) nanoscale-enabling technologies to speed 
up basic research and scientific discovery (3).

For drug delivery, the drug is mixed, encapsulated, entrapped, or attached to the matrix of NPs. Based on the preparation method, nanospheres, nanocapsules, or nanoparticles can be attained. The matrix systems in which the drug is uniformly and physically dispersed are nanospheres, whereas nanocapsules are the systems in which a cavity surrounded by a unique membrane made up of polymers contains the drug. Recently, polymeric biodegradable nanoparticles, which are specifically deliquescent polymers, e.g., polyethylene glycol (PEG) that is a long-circulating particle, have been utilized as potential devices for the delivery of drugs. They have been used as drug delivery devices because of their capability for target specificity, the ability to deliver peptides, proteins, and genes, and acting as carriers for DNA in gene therapy. Nanotechnology allows attaining site-specific drug delivery. The nanotechnology-based drug delivery system is the real need of the day for pharmaceutical companies. Nanoparticles, i.e., objects that are $100 \mathrm{~nm}$-sized or smaller at least in one dimension, are potential candidates as drug carriers. These nanoscale particles are unique in their biological and physiochemical properties because of their tiny sizes. They are capable of crossing tissue and cell barriers and have more reactive surface areas. Therefore, they are very desirable structures for applications in the biomedical domain. To design nanoparticles for delivery of drugs and to attain site-directed action of the pharmaceutical drug at the specific optimal rate and dose plan, the main objective is to control particle surface properties, the size, and release of active pharmacological substances at the target site $(5,7)$.

\section{Tissue Engineering and Bioscaffolds}

Bioscaffolds are artificial objects inserted inside the body. They are used to grow tissue in the damaged or missing parts of the organ in a process known as Tissue Engineering (TE). Tissue engineering is an emerging multidisciplinary field that employs the principles of engineering, chemical science, and biological science with the basic aim of tissue regeneration (8). It is an interdisciplinary area that combines cellular behavior and methods of growing cells on a scaffold (an artificial substrate) in the presence of appropriate biochemical factors needed to develop artificial organs and tissues or regenerate damaged tissues (9-12). A distinguishing characteristic of TE is the ability of the regeneration of the patient's own organs and tissues that not only are completely free of low bio-functionality and poor biocompatibility but also severe immunological rejection (13). It is a technique that involves cells seeding on to a scaffold, followed by in vitro culture to form matured tissue. After the formation of matured tissue, they are fixed inside the body at the site of damage (e.g., fractured cartilage, bone, or skin) as an implant. Regenerative medicine and TE have emerged as the typical field for replacing tissue and organ failed or lost as a result of injury or any other kinds of damage, which are the main health issues for human beings $(14,15)$.

Stem cells can react to morphogen substances, signals, and scaffolds, which are biomimetic of the extracellular matrix (ECM) are the main prerequisites in tissue engineering (16). Sometimes, biomaterials act like scaffolds to maintain, replace, and repair the structure of damaged organs. The developed scaffolds have a few disadvantages including immunological reactions to materials implanted, infection caused by materials, and mechanical failure of materials $(17,18)$.

In TE, the cells that possess the capability of initiation and sustain the process of regeneration are 'switched on' possibly via the genes or growth factors so that they can form a new required variety of functional tissue. This can be possibly achieved by the use of a matrix or a scaffold that guides the architectural or geometrical shape of the new forming tissue and may take place on a customized basis in the damaged area in a single patient or at a more ex vivo industrial level in a bioreactor where the formed tissue construct is again planted in the patient's body (19). Cells are mostly seeded or implanted into an artificial structure that has the capability to support the three-dimensional formation of tissue. These structures are generally known as scaffolds (20). Scaffolds act as support and frameworks for cellular attachment, division, and differentiation that lead to the formation of extracellular matrix (ECM) (21). It should be biocompatible in both degraded and implanted forms (22).

Generally, tissue engineering scaffolds are used with the following main objectives:

1. The major purpose of scaffolds is to provide biochemical factors and cells for cellular migration and attachment (17).

2. They should supply transitory function in damage in the process of tissue regeneration.

3. They should specify an area that shapes the regenerating tissue.

4. They should enable the inward growth of tissue and allow for the incorporation of seeded cells, genes or proteins to speed up the process of tissue regeneration.

5. They should help in the diffusion of nutrients vital to cells and expressed products.

6 . They should have some biological and mechanical effects to change the activity of the cell phase (23).

Thus, scaffolds act as templates in directing the new 
tissue development. Therefore, bioscaffolds are mostly used in the regeneration of cartilages and bones. Recent advances in tissue engineering have led to the birth of third-generation biomaterial scaffolds. Biodegradable and bioactive scaffolds are designed not only to give a transient three-dimensional microenvironment for tissue and cells but also to direct the cellular processes involved in de-novo tissue regeneration (24).

Prerequisites for scaffolds include the following:

1. They should be capable of supporting cellular growth and division and have an acceptable level of toxicity profile and biocompatibility (25).

2. They should possess such mechanical properties that will match to those of tissues present at the site of implantation or have those mechanical properties that are adequate to protect cells from damaging tensile, or compressive or tensile stress without having inhibitory effects on proper biomechanical signals (23).

3. Scaffolds absorption kinetics depend on regenerated tissue. For instants, if a scaffold is going to be used for skeletal system tissue engineering, the rate of degradation of the scaffold biomaterial should be comparatively slow because it has to provide mechanical strength until the regeneration of tissue is nearly finished.

4. It must have the ability for the formation of complex shapes with adequate porosity. Appropriate pore size and high-level porosity are essential to assist diffusion and cell seeding across the whole structure of both nutrients and cells. The optimal pore size is 100 to $500 \mathrm{~nm}$ (13).

5. Biodegradability of scaffolds is an important parameter as they should be imbibed by nearby tissues without the need for surgical removal (26).

6. Scaffolds should mimic the indigenous ECM, which is an endogenous material found around cells, help them bind to tissues, and supply signals that assist the development and morphogenesis of cells.

7. An injectable pre-polymer should be in the form of a liquid and be sterilized without undergoing any structural or chemical change. After the injection, the pre-polymer mixture should bind to the biological surface (25).

Worldwide, a major healthcare issue is the loss of tissue or organ failure due to disease or injury. The donor transplantation of organs and tissues is limited because of the unavailability of compatible donors. Nowadays, the alternative procedures used involve artificial prostheses and mechanical devices that do not repair the damaged organ or tissue function and are not able to integrate into the tissue of the host. Moreover, these artificial prostheses and mechanical devices not only are subject to wear upon due to long-term implantation but also induce inflammation responses in the host (27). Currently, tissue engineering is appearing as a promising alternative to organ or tissue transplantation. By the use of this technology, the loss of tissue or organ failure can be cured either through ex vivo perfusion systems or by the implantation of an engineered biological alternative. The products of TE either can fully perform the function at the treatment time (e.g. encapsulated islets, liver assist devices, etc.) or have the capability to integrate and cause the formation of expected functional tissue at the time of implantation (e.g., chondrocytes fixed in a matrix carrier). In some situations, biomaterials are altered to strengthen the attachment and migration of specific cell populations to replace or repair the injured tissue (28). Cardiovascular tissues like blood vessels $(12,29)$ and heart valves $(30,31)$ are now being engineered by scientists. To give extracorporeal assistance to patients suffering from liver failure, liver-assist systems comprising encapsulated hepatocytes have been used at a clinical level $(31,32)$ and encapsulated pancreatic islets have been implanted in diabetic patients for the cure of diabetes (33). Bioartificial bladder has been created as a replacement engineered organ $(34,35)$ and for patients suffering from kidney failure, a kidney support system consisting of encapsulated urothelial cells is in the process of development $(36,37)$. Moreover, to treat patients with amyotrophic lateral sclerosis, researchers have tried to design and engineer the human nervous system by the use of encapsulation of genetically modified neural cells that secrete ciliary neurotrophic factor (CNTF) (28). In addition, nerve guidance channels have been created for the purpose of peripheral nerve regeneration and spinal cord repair (38, 39). Ophthalmological engineering attempts to develop lens, cornea, and retina tissues (40). For the purpose of bone repair, remarkable development has been made in orthopedic tissue engineering $(41,42)$, ligaments, cartilages, and tendons $(43,44)$ and bovine periosteum on biodegradable polymer matrices $(45,46)$, illustrated the formation of whole joints and small phalanges. By using synthetic matrices and dental fibroblasts, researchers have also attempted to form dental pulps $(42,47)$. For the improvement of vascularization of skin graft, novel strategies have been adopted to produce a vascularized network inside a tissue-engineered skin for the purpose of grafting on deep wounds (48-50).

\section{Tissue Regeneration}

Regeneration can be defined as a form of healing in which a new growth of tissue entirely restores parts of injured tissue to their normal original states. The capability of regeneration of damaged or injured tissues is a typical character across different species. Salamander possesses the ability of whole limb regeneration whereas human beings are restricted in the meaningful regeneration of func- 
tional tissue to the specialized organs such as the liver (5153).

\section{Regenerative Medicine and Nanotechnology}

Regenerative medicine is an arising interdisciplinary area whose aim is to maintain, enhance, or restore tissue and organ functions. Tissue regeneration can be obtained through the combination of materials that act as scaffolds to support the proliferation of cells and provide biological functions $(54,55)$. In mammals, cells act in vivo in reaction to biologicals signals they get from the nearby environment and they are composed of objects in nanoscale. That is why materials used to repair the body have to regenerate the right signals to lead cells to show the desired behavior. Nanotechnology is an outstanding tool to form material structures that not only mimic biological ones but also provide efficient delivery systems (56). Regenerative medicine has brought a high promise for the cure of a large number of human diseases worldwide. In the near future, human diseases like Alzheimer's disease, cancer, Parkinson's disease, spine injury, and osteoporosis might be cured with procedures whose aims are the regeneration of damaged or diseased tissues.

Using the off-the-shelf synthetic product for the regeneration of nonfunctional or injured tissues is a drive for medical science. Nowadays, interest in nanomedicine is increasing due to the application of nanotechnology tools because the formation of materials at the molecular level allows better interactions between biological structures and material surfaces. Since cells are in micrometer dimensions, they are in vivo in immediate connection with the extracellular matrix, which is a substratum having structural characteristics and topography of nanometer size $(57,58)$. The interactions between ECM and cells affect the growth of cells, provide guidance for cell motility, and influence the behavior of cells in general (54). Nanotechnology gives us the opportunity to generate structures, materials, and surfaces with nanoscale characteristics that can copy the cells' natural environment to promote some cellular functions like cell motility, cell adhesion, and cell differentiation. Nanomaterials used in biomedical applications are nanofibres as tissue scaffolds, nanoparticles used for the delivery of molecules like DNA, growth factors, and drugs, and nanodevices or surface-altered implantable entities (56). In TE, the combination of these materials is a good example of the potency of nanotechnology applications in regenerative medicine $(59,60)$. The main aim of regenerative medicine is the in vivo regeneration or in vitro formation of complicated functional organs that consist of a scaffold produced from natural or synthetic materials that are full of living cells. Preferably, they should be used due to stem cells' potential to produce all kinds of tissues and their limitless ability of self-renewal. The success of the TE approach could be greatly increased by the functionalization of porous scaffolds with different biological molecules (based on targeted cells) or encapsulation of nanoparticles like genes, drugs, or growth factors $(61,62)$. However, there are major problems to this strategy, including the isolation of stem cells from the patient, followed by their proliferation and culture in a biological reactor and long-time span before the engineered hybrid construct is placed back into the patient; thus, we need well established standard methods in the future (56). In the last two decades, Robert Langer, Anthony Atala, and other scientists established the areas of regenerative medicine and TE (Kwon et al., 2008). Ongoing advancement in the field of regenerative medicine is a potential way of the stimulation of the body's repair mechanisms for the regeneration of damaged or injured tissues (56).

\section{Strategies for Regenerative Medicine}

"The promise of regenerative medicine is the complete, functional repair of human tissue damaged by disease or injury" (CIRM, 2012). Towards regenerative medicine in humans concerning "the process of replacing, engineering, or regenerating human cells, tissues, or organs to restore or establish normal function" (63), there are three broad strategies at present. The most closely associated strategy with regenerative medicine is the strategy of stem cell therapy. As "stem cells are responsible for engineering an organ's original complexity during development, it holds that they should be capable of recapitulating complexity after injury". The current advancement in the area shows great potential $(64,65)$ but still, much research is needed before such therapeutic approaches are provided to a wide number of patients. In animals that have the ability of tissue regeneration, stem and progenitor cells are first arranged into a blastema at the site of tissue damage (66). Another theory says that the adult mammal's immune system prevents regeneration by the inhibition of this arrangement and alternatively, represents a strong bias for quick recovery and fast return of movement (67). Therefore, another promising approach in TE directs to regulate the immune system to allow endogenous regeneration (68). Indeed, there is a firm relationship between the "development of adaptive immunity and the loss of regenerative ability" (69). In spite of insufficient understanding of procedures involved in the regeneration process, advancement has been made in implementing the "principles of regenerative medicine to humans" and stem cell therapies' scope will be enhanced 
with a more deep understanding of "limited regenerative capacity of humans". Currently, most successful tissue engineering plans depend on macroporous scaffolds that facilitate attachment at the beginning and following the differentiation cues for seeded stem cells. After achieving success for relatively simple tissues like blood vessels (70) and bladders (71), the more complicated metabolic organs like the kidneys and liver need more advanced and complex biomimetic scaffolds, which will have the ability to give multilayer information to differentiating cells $(72,73)$. "To deliver on the promise of "off-the-shelf" organs" and for the successful stimulation of in vivo tissue regeneration, the extending area of nanomedicine must be mingled into the tissue engineering strategy (74).

\section{CRISPR/Cas9 System}

The clustered regularly interspaced short palindromic repeats (CRISPR)-associated protein9 (Cas9) system is a natural defense mechanism of bacteria for protection against plasmid transfer and phage infection. It has been adapted as a platform for use as a strong RNA-directed DNA targeting tool for genome imaging, genome editing, epigenetic modulation, transcriptional perturbation, and epigenetic modulation. By the use of this technique, one can accurately manipulate nearly any specific sequence of the genome with the help of a short stretch of guide RNA (75), which allows the correction of "disease-causing mutations", explanation of the function of genes involved in development and progression of diseases, and "inactivation of activated oncogenes or activation of deactivated cancer suppressor genes when utilizing a fusion protein of nuclease-deficient Cas9 and effector domain" (7679). Additionally, this programmable endonuclease technology allows scientists to know about the function of various genes at the same time by targeting several genomic loci in one experiment (80). This will help increase our knowledge of pathological processes that are involved in large sets of mutations or genes, like tumor development. By the use of libraries of single-guide RNA (sgRNA), CRISPR-based genome-wide screens can be used to identify and quickly determine drug targets and identify disease-resistance genes, like oncogenes or novel tumor suppressors $(81,82)$. CRISPR-Cas9-mediated genome engineering offers great potential for the treatment of genetic diseases, neurodegeneration, various types of cancer, Duchenne muscular dystrophy, cystic fibrosis, immunological disorders, viral infections, sickle cell anemia, and cardiovascular diseases (83-86).

The CRISPRs are important genomic factors of many bacteriophage-resistant archaea and bacteria. Moreover,
Cas9 is a CRISPR-linked endonuclease along with helicase domains and putative nuclease that can be localized to a specific portion of DNA and cause double-strand breaks under the guidance of trans-activating CRISPR RNA (tracrRNA): CRISPR RNA (crRNA) duplex (87-89). Studies show that the "tracrRNA:crRNA" duplex guides the CRISPRassociated protein Cas9 to utilize two sites HNH and RuvC and break the double strands in the targeted DNA that is complementary to crRNA (90-92).

The dual trancrRNA: crRNA was developed to use as a single-guide RNA (sgRNA) for the purpose of genome engineering. It consists of a " 5 ' end 20-nucleotide sequence determining the DNA target site according to Watson-Crick base pairing and a 3' end double-stranded structure binding Cas9" (91). The sgRNA has the potential to guide the CRISPR-Cas9 to the desired DNA sequence along with adjacent protospacer-adjacent motif (PAM) by altering the sequence of gRNA (93-95). The CRISPR-Cas9 has proven to be a successful genome editing tool in human cells $(80,96,97)$.

\section{CRISPR/Cas9 Systems in Tissue Engineering}

In tissue engineering, the present uses of CRISPR/Cas systems have emphasized to address the tissue architecture formation, immune response circumvention, cell differentiation, and disease model development. For the application of tissue engineering, stem cells are great cell sources with huge potential but the directed differentiation of these stem cells is still a non-trivial challenge. For the improvement of osteogenic potential of Adiposederived Stem Cells (ASC), the CRISPR/Cas system has been utilized to edit their genomes by "exchanging bone morphogenetic protein (BMP) antagonist-encoding sequences (noggin) with BMP agonist-encoding sequence (BMP-2)" (98). By the replacement of noggin with BMP-2, "the cellular mechanism that upregulates the BMP antagonist is harnessed to express the BMP agonist under noggin promotion". "This theoretically would direct the ASC population towards an osteogenic lineage, even under stimuli that would inhibit BMP production". This usage of CRISPR/Cas systems to direct differentiation of stem cells to a particular lineage is a beneficial replacement to commonly used clinical applications of exogenous recombinant growth factors $(99,100)$. Likewise, other researchers have utilized CRISPR/Cas systems for direct differentiation for use in disease modeling and tissue engineering. Scientists have used this system for editing intestinal stem cells of humans to understand the pathways that lead to the development of colorectal carcinoma (101). Investigators used CRISPR/Cas systems for editing the genomes of induced pluripotent stem cells (iPS) to produce isogenic cell lines with or without mutations (102). These isogonic cell lines have appli- 
cations in disease modeling and tissue engineering. Recently, the optogenetic control of transcription from endogenous genes has been obtained through developing a CIBN-dCas9 fusion protein, which dimerizes with transcriptional activator CRY2VP64 at exposure to blue light (103). This light-activated CRISPR/Cas9 effector (LACE) can be utilized to direct cell differentiation with the additional benefit of spatiotemporal control. This ability to control the pattern and timing of differentiation could be utilized as a strategy to form biomimetic tissue architecture in tissue-engineered constructs. The use of CRISPR/Cas9 systems in tissue engineering will rely on the capability to reduce off-target events and restricted exposure to the activity of Cas is a crucial fact. Systems like LACE could confine the exposure to the activity of Cas when it is integrated into the genome. Care should be taken to avoid random integrations, possibly through targeting safe harbor loci for the integration of the CRISPR/Cas system $(77,104,105)$.

Taken together, these examples of the use of CRISPR/Cas systems in tissue engineering are the signs of an emerging push towards the use of synthetic and molecular biology to help in the solution of problems faced in this area. The future utilization of CRISPR/Cas systems in the field of tissue engineering will not only continue to address tissue architecture formation, immune response circumvention, disease model development, and cell differentiation, but also possibly focus on spatiotemporal programming, angiogenesis, immunomodulation/immunoengineering, and patterning. Although there has been advancement in stem cell engineering for the promotion of angiogenesis, the most used techniques need specialized knowledge to reduce accessibility to a vast array of researchers $(106,107)$. An example is hepatocyte growth factor-secreting umbilical cord stem cell engineering by the use of TALEN to induce angiogenesis (108). One of the advantages of CRISPR/Cas systems is that they would help researchers with lacked specialized knowledge in protein engineering to work on these developments and they might be able to produce even much more complicated multifactor-secreting cells. Strategies that use CRISPR/Cas systems for regulation of apoptosis, differentiation, and homing of stem cells need to be established as these are the main areas of attention for stem cell engineering (109). Moreover, the ability to address all these areas with one single system is an attractive and logical solution. Moreover, complex GRN has promised to be utilized for the generation of tissue architectures that will mimic native body tissues in both function and form, affecting various applications in the field of tissue engineering, like whole-organ engineering, 3D microtissue development for in vitro assays and multi-layered tissues (e.g. vascular grafts), and disease modeling. It is also plausible to use GRN to assert spatiotemporal control for the introduction of immunomodulation/immunoengineering and angiogenesis solutions to the area. For these spatiotemporal regulation systems, CRISPR/Cas-based GRN will respond to a range of both exogenous and endogenous physicochemical stimuli to initiate complicated behaviors that will permit the timely release of cytokines and growth factors; it also regulates the expression of cellular receptors, all under spatiotemporal control (109). The future use of CRISPR/Cas systems in tissue engineering will be vast and restricted only due to our understanding of cellular processes that are continuously being studied, the future will be bright and promising $(78,110,111)$.

\section{Future Perspectives}

While notable development has been made in the field of tissue engineering and nanotechnology, various challenges still exist in the utilization of nanotechnology to design more complicated tissues. There is a need for a wellorganized study of biodegradability and biocompatibility of recently manufactured nanoparticles for their integration into clinical trials. More advancement in this field needs ongoing collaborations and interactions among researchers from various disciplines and corporation with the funding and regulatory firms. Moreover, the development and research expenses for tissue engineering and regenerative medicines are too high and there is a need to make these systems cost-effective. Thus, the advanced approach of applications of nanotechnology to regenerative medicine and CRISPR will definitely revolutionize the basis of treatment, prevention, and diagnosis of various diseases.

\section{Footnotes}

Authors' Contribution: The manuscript was written by Qurban Ali and Sabeen Malik. The editing was carried out by Muhammad Nadeem Hafeez and Said Salman under the supervision of Arif Malik. The final corrections and editing were done by Qurban Ali. Final approval for publication was given by all authors.

Conflict of Interests: The authors declare no conflict of interest in the manuscript.

Funding/Support: There is no funding for the present manuscript.

\section{References}

1. Farokhzad OC, Langer R. Nanomedicine: developing smarter therapeutic and diagnostic modalities. Adv Drug Deliv Rev. 
2006;58(14):1456-9. doi: 10.1016/j.addr.2006.09.011. [PubMed: 17070960].

2. Whitesides GM. The 'right' size in nanobiotechnology. Nat Biotechnol. 2003;21(10):1161-5. doi: 10.1038/nbt872. [PubMed: 14520400].

3. Alexis F, Rhee JW, Richie JP, Radovic-Moreno AF, Langer R, Farokhzad OC. New frontiers in nanotechnology for cancer treatment. Urol Oncol. 2008;26(1):74-85. doi: 10.1016/j.urolonc.2007.03.017. [PubMed: 18190835].

4. Shin WK, Cho J, Kannan AG, Lee YS, Kim DW. Cross-linked composite gel polymer electrolyte using mesoporous methacrylatefunctionalized $\mathrm{SiO} 2$ nanoparticles for lithium-ion polymer batteries. Sci Rep. 2016;6:26332. doi: 10.1038/srep26332. [PubMed: 27189842]. [PubMed Central: PMC4870681].

5. Nikam AP, Mukesh P, Haudhary S. Nanoparticles-an overview. J Drug Deliv Ther. 2014;3:1121-7.

6. Mohamed A, Xing MM. Nanomaterials and nanotechnology for skin tissue engineering. Int J Burns Trauma. 2012;2(1):29-41. [PubMed: 22928165]. [PubMed Central: PMC3415966].

7. Roh DS, Li EB, Liao EC. CRISPR Craft: DNA editing the reconstructive ladder. Plast Reconstr Surg. 2018;142(5):1355-64. doi: 10.1097/PRS.0000000000004863. [PubMed: 30511992].

8. Vasita R, Katti DS. Nanofibers and their applications in tissue engineering. Int $J$ Nanomedicine. 2006;1(1):15-30. doi: 10.2147/nano.2006.1.15. [PubMed: 17722259]. [PubMed Central: PMC2426767]

9. Mikos AG, Sarakinos G, Leite SM, Vacanti JP, Langer R. Laminated three-dimensional biodegradable foams for use in tissue engineering. Biomaterials. 1993;14(5):323-30. doi: 10.1016/0142-9612(93)900498. [PubMed: 8507774].

10. Liu C, Xia Z, Czernuszka JT. Design and development of threedimensional scaffolds for tissue engineering. Chem Eng Res Des. 2007;85(7):1051-64. doi: 10.1205/cherd06196.

11. Stevens MM, George JH. Exploring and engineering the cell surface interface. Science. 2005;310(5751):1135-8. doi: 10.1126/science.1106587. [PubMed: 16293749].

12. Bouten CVC, Smits A, Baaijens FPT. Can we grow valves inside the heart? Perspective on material-based in situ heart valve tissue engineering. Front Cardiovasc Med. 2018;5:54. doi: 10.3389/fcvm.2018.00054. [PubMed: 29896481]. [PubMed Central: PMC5987128].

13. Ikada $Y$. Challenges in tissue engineering. $J R$ Soc Interface. 2006;3(10):589-601. doi: 10.1098/rsif.2006.0124. [PubMed: 16971328]. [PubMed Central: PMC1664655].

14. Motaung SC, Di Cesare PE, Reddi AH. Differential response of cartilage oligomeric matrix protein (COMP) to morphogens of bone morphogenetic protein/transforming growth factor-beta family in the surface, middle and deep zones of articular cartilage. J Tissue Eng Regen Med. 2011;5(6):e87-96. doi: 10.1002/term.358. [PubMed: 21604381].

15. Saw SK, Purwar R, Nandy S, Ghose J, Sarkhel G. Fabrication, characterization, and evaluation of luffa cylindrica fiber reinforced epoxy composites. BioResources. 2013;8(4). doi: 10.15376/biores.8.4.4805-4826.

16. Becerra J, Andrades JA, Guerado E, Zamora-Navas P, Lopez-Puertas JM, Reddi AH. Articular cartilage: Structure and regeneration. Tissue Eng Part B Rev. 2010;16(6):617-27. doi: 10.1089/ten.TEB.2010.0191. [PubMed: 20836752].

17. O'Brien FJ. Biomaterials \& scaffolds for tissue engineering. Materials Today. 2011;14(3):88-95. doi: 10.1016/s1369-7021(11)70058-x.

18. Raghunath J, Rollo J, Sales KM, Butler PE, Seifalian AM. Biomaterials and scaffold design: Key to tissue-engineering cartilage. Biotechnol Appl Biochem. 2007;46(Pt 2):73-84. doi: 10.1042/BA20060134. [PubMed: 17227284].

19. Williams D. Benefit and risk in tissue engineering. Materials Today. 2004;7(5):24-9. doi: 10.1016/s1369-7021(04)00232-9.

20. Patel H, Bonde M, Srinivasan G. Biodegradable polymer scaffold for tissue engineering. Trends Biomater Artif Organs. 2011;25(1):20-9.

21. Agrawal CM, Ray RB. Biodegradable polymeric scaffolds for mus- culoskeletal tissue engineering. J Biomed Mater Res. 2001;55(2):14150. doi: 10.1002/1097-4636(200105)55:2<141::aid-jbm1000>3.0.co;2-j. [PubMed: 11255165].

22. Gomes ME, Ribeiro AS, Malafaya PB, Reis RL, Cunha AM. A new approach based on injection moulding to produce biodegradable starch-based polymeric scaffolds: Morphology, mechanical and degradation behaviour. Biomaterials. 2001;22(9):883-9. doi: 10.1016/s0142-9612(00)00211-8.

23. Sokolsky-Papkov M, Agashi K, Olaye A, Shakesheff K, Domb AJ. Polymer carriers for drug delivery in tissue engineering. Adv Drug Deliv Rev. 2007;59(4-5):187-206. doi: 10.1016/j.addr.2007.04.001. [PubMed: 17540473].

24. Hutmacher DW. Scaffolds in tissue engineering bone and cartilage. Biomaterials. 2000;21(24):2529-43. doi: 10.1016/s0142-9612(00)00121-6.

25. Gunatillake PA, Adhikari R. Biodegradable synthetic polymers for tissue engineering. Eur Cell Mater. 2003;5:1-16. discussion 16. doi: 10.22203/ecm.v005a01. [PubMed: 14562275].

26. Gu H, Yue Z, Leong WS, Nugraha B, Tan LP. Control of in vitro neural differentiation of mesenchymal stem cells in 3D macroporous, cellulosic hydrogels. Regen Med. 2010;5(2):245-53. doi: 10.2217/rme.09.89. [PubMed: 20210584].

27. Maguire JK Jr, Coscia MF, Lynch MH. Foreign body reaction to polymeric debris following total hip arthroplasty. Clin Orthop Relat Res. 1987;(216):213-23. [PubMed: 3545602].

28. Chapekar MS. Tissue engineering: challenges and opportunities. J Biomed Mater Res. 2000;53(6):617-20. doi: 10.1002/10974636(2000)53:6<617::aid-jbm1>3.0.co;2-c. [PubMed: 11074418].

29. Hoffman T, Khademhosseini A, Langer R. Chasing the paradigm: Clinical translation of 25 years of tissue engineering. Tissue Eng Part A. 2019;25(9-10):679-87. doi: 10.1089/ten.TEA.2019.0032. [PubMed: 30727841]. [PubMed Central: PMC6533781].

30. Hoes MF, Bomer N, van der Meer P. Concise review: The current state of human in vitro cardiac disease modeling: A focus on gene editing and tissue engineering. Stem Cells Transl Med. 2019;8(1):6674. doi: 10.1002/sctm.18-0052. [PubMed: 30302938]. [PubMed Central: PMC6312446].

31. Fujita J, Tohyama S, Kishino Y, Okada M, Morita Y. Concise review: Genetic and epigenetic regulation of cardiac differentiation from human pluripotent stem cells. Stem Cells. 2019;37(8):992-1002. doi: 10.1002/stem.3027. [PubMed: 31021504].

32. Cruvinel E, Ogusuku I, Cerioni R, Goncalves J, Goes ME, Silva AC, et al. Long-term single-cell passaging of human iPSCs fully supports pluripotency and high-efficient trilineage differentiation capacity. BioRxiv. 2019:663047. doi: 10.1101/663047.

33. Sessions JW, Armstrong DG. Biologic tools for genetic engineering chronic wounds. Recent clinical techniques, results, and research in wounds. Springer; 2018. doi: 10.1007/15695_2017_90.

34. Aquilina B, Cauchi RJ. Modelling motor neuron disease in fruit flies: Lessons from spinal muscular atrophy.J Neurosci Methods. 2018;310:311. doi: 10.1016/j.jneumeth.2018.04.003. [PubMed: 29649521].

35. Bellen HJ, Wangler MF, Yamamoto S. The fruit fly at the interface of diagnosis and pathogenic mechanisms of rare and common human diseases. Hum Mol Genet. 2019;28(R2):R207-14. doi: 10.1093/hmg/ddz135. [PubMed: 31227826]. [PubMed Central: PMC6872428].

36. Meltzer H, Marom E, Alyagor I, Mayseless O, Berkun V, SegalGilboa N, et al. Tissue-specific (ts)CRISPR as an efficient strategy for in vivo screening in Drosophila. Nat Commun. 2019;10(1):2113. doi: 10.1038/s41467-019-10140-0. [PubMed: 31068592]. [PubMed Central: PMC6506539].

37. Garreta E, Gonzalez F, Montserrat N. Studying kidney disease using tissue and genome engineering in human pluripotent stem cells. Nephron. 2018;138(1):48-59. doi: 10.1159/000480710. [PubMed: 28988229].

38. Senturk M, Bellen HJ. Genetic strategies to tackle neurological 
diseases in fruit flies. Curr Opin Neurobiol. 2018;50:24-32. doi: 10.1016/j.conb.2017.10.017. [PubMed: 29128849]. [PubMed Central: PMC5940587].

39. Willsey AJ, Morris MT, Wang S, Willsey HR, Sun N, Teerikorpi N, et al. The psychiatric cell map initiative: A convergent systems biological approach to illuminating key molecular pathways in neuropsychiatric disorders. Cell. 2018;174(3):505-20. doi: 10.1016/j.cell.2018.06.016. [PubMed: 30053424]. [PubMed Central: PMC6247911].

40. Port F, Strein C, Stricker M, Rauscher B, Heigwer F, Zhou J, et al. A largescale resource for tissue-specific CRISPR mutagenesis in Drosophila. bioRxiv. 2019:636076. doi: 10.1101/636076.

41. Repetti GG, Toepfer CN, Seidman JG, Seidman CE. Novel therapies for prevention and early treatment of cardiomyopathies. Circ Res. 2019;124(11):1536-50. doi: 10.1161/CIRCRESAHA.119.313569. [PubMed: 31120825].

42. Buduru SD, Gulei D, Zimta AA, Tigu AB, Cenariu D, Berindan-Neagoe I. The potential of different origin stem cells in modulating oral bone regeneration processes. Cells. 2019;8(1). doi: 10.3390/cells8010029. [PubMed: 30625993]. [PubMed Central: PMC6356555].

43. Dyikanov DT, Vasiluev PA, Rysenkova KD, Aleksandrushkina NA, Tyurin-Kuzmin PA, Kulebyakin KY, et al. Optimization of CRISPR/cas9 technology to knock out genes of interest in aneuploid cell lines. Tissue Eng Part C Methods. 2019;25(3):168-75. doi: 10.1089/ten.TEC.2018.0365. [PubMed: 30747044].

44. Ju XD, Xu J, Sun ZS. CRISPR editing in biological and biomedical investigation. J Cell Biochem. 2018;119(1):52-61. doi: 10.1002/jcb.26154. [PubMed: 28543738].

45. Weidmann AG. Frontiers in CRISPR. ACS Chem Biol. 2018;13(2):296-304. doi: 10.1021/acschembio.8b00135. [PubMed: 29448764].

46. Hurtley S, Mao S. Taking CRISPR technology further. Science. 2018;360(6387):393-4. doi: 10.1126/science.360.6387.393-d.

47. Hernandez-Monjaraz B, Santiago-Osorio E, Monroy-Garcia A Ledesma-Martinez E, Mendoza-Nunez VM. Mesenchymal stem cells of dental origin for inducing tissue regeneration in periodontitis: A mini-review. Int J Mol Sci. 2018;19(4). doi: 10.3390/ijms19040944. [PubMed: 29565801]. [PubMed Central: PMC5979585].

48. Liu CY, Wang HC. The fibroblast of radicular cyst facilitate osteoclastogenesis via the autocrine of Fibronectin containing extra domain A. Oral Dis. 2019;25(4):1136-46. doi: 10.1111/odi.13064. [PubMed: 30770599].

49. Boyce ST, Lalley AL. Tissue engineering of skin and regenerative medicine for wound care. Burns Trauma. 2018;6:4. doi: 10.1186/s41038017-0103-y. [PubMed: 30009192]. [PubMed Central: PMC6040609].

50. Kashpur O, Smith A, Mukhamedshina N, Baskin J, Shamis Y, Hewitt K, et al. Induced pluripotent stem cells to generate skin tissue models. Skin Tissue Models. Academic Press; 2018. p. 399-419. doi: 10.1016/b9780-12-810545-0.00017-6.

51. Chandra P, Atala A. Engineering blood vessels and vascularized tissues: Technology trends and potential clinical applications. Clin Sci (Lond). 2019;133(9):1115-35. doi: 10.1042/CS20180155. [PubMed: 31088895].

52. Loesch R, Desbois-Mouthon C, Colnot S. Potentials of CRISPR in liver research and therapy. Clin Res Hepatol Gastroenterol. 2019;43(1):5-11. doi: 10.1016/j.clinre.2018.05.001. [PubMed: 29884474].

53. Chen Z, Cai X, Li M, Yan L, Wu L, Wang X, et al. CRISPR/Cas9-based liverderived reporter cells for screening of mPGES-1 inhibitors. J Enzyme Inhib Med Chem. 2019;34(1):799-807. doi: 10.1080/14756366.2019.1587416. [PubMed: 30879343]. [PubMed Central: PMC6427568].

54. Lutolf MP, Hubbell JA. Synthetic biomaterials as instructive extracellular microenvironments for morphogenesis in tissue engineering. Nat Biotechnol. 2005;23(1):47-55. doi: 10.1038/nbt1055. [PubMed: 15637621].

55. Goldberg M, Langer R, Jia X. Nanostructured materials for applications in drug delivery and tissue engineering. J Biomater Sci Polym Ed. 2007;18(3):241-68. doi: 10.1163/156856207779996931. [PubMed: 17471764]. [PubMed Central: PMC3017754]
56. Engel E, Michiardi A, Navarro M, Lacroix D, Planell JA. Nanotechnology in regenerative medicine: The materials side. Trends Biotechnol. 2008;26(1):39-47. doi: 10.1016/j.tibtech.2007.10.005. [PubMed 18036685].

57. Gattazzo F, Urciuolo A, Bonaldo P. Extracellular matrix: A dynamic microenvironment for stem cell niche. Biochim Biophys Acta. 2014;1840(8):2506-19. doi: 10.1016/j.bbagen.2014.01.010. [PubMed: 24418517]. [PubMed Central: PMC4081568].

58. Ingber DE. Mechanical signaling and the cellular response to extracellular matrix in angiogenesis and cardiovascular physiology. Circ Res. 2002;91(10):877-87. doi: 10.1161/01.res.0000039537.73816.e5. [PubMed: 12433832].

59. Shi J, Votruba AR, Farokhzad OC, Langer R. Nanotechnology in drug delivery and tissue engineering: From discovery to applications. Nano Lett. 2010;10(9):3223-30. doi: 10.1021/nl102184c. [PubMed: 20726522]. [PubMed Central: PMC2935937].

60. Lu JM, Wang X, Marin-Muller C, Wang H, Lin PH, Yao Q, et al Current advances in research and clinical applications of PLGA based nanotechnology. Expert Rev Mol Diagn. 2009;9(4):325-41. doi: 10.1586/erm.09.15. [PubMed: 19435455]. [PubMed Central PMC2701163].

61. Verma S, Domb AJ, Kumar N. Nanomaterials for regenerative medicine. Nanomedicine (Lond). 2011;6(1):157-81. doi: 10.2217/nnm.10.157. [PubMed: 21182426].

62. Singh S. Nanomedicine-nanoscale drugs and delivery systems. $J$ Nanosci Nanotechnol. 2010;10(12):7906-18. doi: 10.1166/jnn.2010.3617. [PubMed: 21121278].

63. Mason C, Dunnill P. A brief definition of regenerative medicine. Regen Med.2008;3(1):1-5. doi: 10.2217/17460751.3.1.1. [PubMed: 18154457].

64. Davatchi F, Abdollahi BS, Mohyeddin M, Shahram F, Nikbin B. Mesenchymal stem cell therapy for knee osteoarthritis. Preliminary report of four patients. Int J Rheum Dis. 2011;14(2):211-5. doi: 10.1111/j.1756185X.2011.01599.x. [PubMed: 21518322].

65. Rama P, Matuska S, Paganoni G, Spinelli A, De Luca M, Pellegrini G. Limbal stem-cell therapy and long-term corneal regeneration. $N$ Engl JMed.2010;363(2):147-55. doi:10.1056/NEJMoa0905955. [PubMed: 20573916].

66. Fadini GP, Agostini C, Avogaro A. Autologous stem cell therapy for peripheral arterial disease meta-analysis and systematic review of the literature. Atherosclerosis. 2010;209(1):10-7. doi: 10.1016/j.atherosclerosis.2009.08.033. [PubMed: 19740466].

67. Godwin JW, Brockes JP. Regeneration, tissue injury and the immune response. J Anat. 2006;209(4):423-32. doi: 10.1111/j.14697580.2006.00626.x. [PubMed: 17005015]. [PubMed Central: PMC2100360].

68. Pearl JI, Lee AS, Leveson-Gower DB, Sun N, Ghosh Z, Lan F, et al. Short-term immunosuppression promotes engraftment of embryonic and induced pluripotent stem cells. Cell Stem Cell. 2011;8(3):30917. doi: 10.1016/j.stem.2011.01.012. [PubMed: 21362570]. [PubMed Central: PMC3061351].

69. Flajnik MF, Kasahara M. Origin and evolution of the adaptive immune system: Genetic events and selective pressures. Nat Rev Genet 2010;11(1):47-59. doi: 10.1038/nrg2703. [PubMed: 19997068]. [PubMed Central: PMC3805090].

70. L'Heureux N, Paquet S, Labbe R, Germain L, Auger FA. A completely biological tissue-engineered human blood vessel. FASEB J.1998;12(1):4756. doi:10.1096/fasebj.12.1.47. [PubMed: 9438410].

71. Sun W, Lee J, Zhang S, Benyshek C, Dokmeci MR, Khademhosseini A. Engineering precision medicine. Adv Sci (Weinh). 2019;6(1):1801039. doi: 10.1002/advs.201801039. [PubMed: 30643715]. [PubMed Central: PMC6325626].

72. Messner F, Guo Y, Etra JW, Brandacher G. Emerging technologies in organ preservation, tissue engineering and regenerative medicine: A blessing or curse for transplantation? Transpl Int. 2019;32(7):673-85 doi: 10.1111/tri.13432. [PubMed: 30920056]. 
73. Song HG, Rumma RT, Ozaki CK, Edelman ER, Chen CS. Vascular tissue engineering: Progress, challenges, and clinical promise. Cell Stem Cell. 2018;22(3):340-54. doi: 10.1016/j.stem.2018.02.009. [PubMed: 29499152]. [PubMed Central: PMC5849079].

74. Cassidy JW. Nanotechnology in the regeneration of complex tissues. Bone Tissue Regen Insights. 2014;5:25-35. doi: 10.4137/BTRI.S12331. [PubMed: 26097381]. [PubMed Central: PMC4471123].

75. Charpentier E, Doudna JA. Biotechnology: Rewriting a genome. Na ture. 2013;495(7439):50-1. doi:10.1038/495050a. [PubMed: 23467164].

76. Charpentier E, Marraffini LA. Harnessing CRISPR-Cas9 immunity for genetic engineering. Curr Opin Microbiol. 2014;19:114-9. doi: 10.1016/j.mib.2014.07.001. [PubMed: 25048165]. [PubMed Central: PMC4155128].

77. Doudna JA, Charpentier E. Genome editing. The new frontier of genome engineering with CRISPR-Cas9. Science. 2014;346(6213):1258096. doi: 10.1126/science.1258096. [PubMed: 25430774].

78. Hsu PD, Lander ES, Zhang F. Development and applications of CRISPR-Cas9 for genome engineering. Cell. 2014;157(6):1262-78. doi: 10.1016/j.cell.2014.05.010. [PubMed: 24906146]. [PubMed Central: PMC4343198].

79. Zhang Y, Heidrich N, Ampattu BJ, Gunderson CW, Seifert HS, Schoen $\mathrm{C}$, et al. Processing-independent CRISPR RNAs limit natural transformation in Neisseria meningitidis. Mol Cell. 2013;50(4):488-503. doi 10.1016/j.molcel.2013.05.001. [PubMed: 23706818]. [PubMed Central: PMC3694421].

80. Cong L, Ran FA, Cox D, Lin S, Barretto R, Habib N, et al. Multiplex genome engineering using CRISPR/Cas systems. Science. 2013;339(6121):819-23. doi: 10.1126/science.1231143. [PubMed: 23287718]. [PubMed Central: PMC3795411].

81. Dominguez AA, Lim WA, Qi LS. Beyond editing: repurposing CRISPRCas9 for precision genome regulation and interrogation. Nat Rev Mol Cell Biol. 2016;17(1):5-15. doi: 10.1038/nrm.2015.2. [PubMed: 26670017]. [PubMed Central: PMC4922510].

82. Shalem O, Sanjana NE, Zhang F. High-throughput functional genomics using CRISPR-Cas9. Nat Rev Genet. 2015;16(5):299-311. doi: 10.1038/nrg3899. [PubMed: 25854182]. [PubMed Central: PMC4503232].

83. Barrangou R, Doudna JA. Applications of CRISPR technologies in research and beyond. Nat Biotechnol. 2016;34(9):933-41. doi: 10.1038/nbt.3659. [PubMed: 27606440].

84. Maeder ML, Gersbach CA. Genome-editing technologies for gene and cell therapy. Mol Ther. 2016;24(3):430-46. doi: 10.1038/mt.2016.10. [PubMed: 26755333]. [PubMed Central: PMC4786923].

85. Strong A, Musunuru K. Genome editing in cardiovascular diseases. Nat Rev Cardiol. 2017;14(1):11-20. doi: 10.1038/nrcardio.2016.139. [PubMed: 27609628].

86. Xiong X, Chen M, Lim WA, Zhao D, Qi LS. CRISPR/Cas9 for human genome engineering and disease research. Annu Rev Genomics Hum Genet. 2016;17:131-54. doi: 10.1146/annurev-genom-083115-022258. [PubMed: 27216776].

87. Brouns SJ, Jore MM, Lundgren M, Westra ER, Slijkhuis RJ, Snijders AP, et al. Small CRISPR RNAs guide antiviral defense in prokaryotes. Science. 2008;321(5891):960-4. doi: 10.1126/science.1159689. [PubMed: 18703739]. [PubMed Central: PMC5898235].

88. Deltcheva E, Chylinski K, Sharma CM, Gonzales K, Chao Y, Pirzada ZA, et al. CRISPR RNA maturation by trans-encoded small RNA and host factor RNase III. Nature. 2011;471(7340):602-7. doi: 10.1038/nature09886. [PubMed: 21455174]. [PubMed Central: PMC3070239].

89. Marraffini LA, Sontheimer EJ. CRISPR interference limits horizontal gene transfer in staphylococci by targeting DNA. Science. 2008;322(5909):1843-5. doi: 10.1126/science.1165771. [PubMed: 19095942]. [PubMed Central: PMC2695655].

90. Gasiunas G, Barrangou R, Horvath P, Siksnys V. Cas9-crRNA ribonucleoprotein complex mediates specific DNA cleavage for adaptive immunity in bacteria. Proc Natl Acad Sci U S A. 2012;109(39):E2579-86. doi: 10.1073/pnas.1208507109. [PubMed: 22949671]. [PubMed Central: PMC3465414]

91. Jinek M, Chylinski K, Fonfara I, Hauer M, Doudna JA, Charpentier E. A programmable dual-RNA-guided DNA endonuclease in adaptive bacterial immunity. Science. 2012;337(6096):816-21. doi: 10.1126/science.1225829. [PubMed: 22745249]. [PubMed Central: PMC6286148].

92. Yang X. Applications of CRISPR-Cas9 mediated genome engineering. Mil Med Res. 2015;2:11. doi: 10.1186/s40779-015-0038-1. [PubMed: 25984354]. [PubMed Central: PMC4433013].

93. Anders C, Niewoehner O, Duerst A, Jinek M. Structural basis of PAMdependent target DNA recognition by the Cas9 endonuclease. Nature. 2014;513(7519):569-73. doi: 10.1038/nature13579. [PubMed: 25079318]. [PubMed Central: PMC4176945].

94. Sternberg SH, Redding S, Jinek M, Greene EC, Doudna JA. DNA interrogation by the CRISPR RNA-guided endonuclease Cas9. Nature. 2014;507(7490):62-7. doi: 10.1038/nature13011. [PubMed: 24476820]. [PubMed Central: PMC4106473].

95. Szczelkun MD, Tikhomirova MS, Sinkunas T, Gasiunas G, Karvelis T, Pschera P, et al. Direct observation of R-loop formation by single RNA-guided Cas9 and Cascade effector complexes. Proc Natl Acad Sci USA. 2014;111(27):9798-803. doi: 10.1073/pnas.1402597111. [PubMed: 24912165]. [PubMed Central: PMC4103346].

96. Jinek M, East A, Cheng A, Lin S, Ma E, Doudna J. RNA-programmed genome editing in human cells. Elife. 2013;2. e00471. doi: 10.7554/eLife.00471. [PubMed: 23386978]. [PubMed Central: PMC3557905].

97. Mali P, Yang L, Esvelt KM, Aach J, Guell M, DiCarlo JE, et al. RNA-guided human genome engineering via Cas9. Science. 2013;339(6121):823-6. doi: 10.1126/science.1232033. [PubMed: 23287722]. [PubMed Central: PMC3712628].

98. Davis B, Farhang N; Bowles. Use of CRISPR genome-editing technology to promote osteogenic differentiation in human adipose-derived mesenchymal stem cells (hAD-MSCs). 2015.

99. Zhang XH, Tee LY, Wang XG, Huang QS, Yang SH. Off-target Effects in CRISPR/Cas9-mediated Genome Engineering. Mol Ther Nucleic Acids. 2015;4. e264. doi: 10.1038/mtna.2015.37. [PubMed: 26575098]. [PubMed Central: PMC4877446].

100. Ousterout DG, Kabadi AM, Thakore PI, Majoros WH, Reddy TE, Gersbach CA. Multiplex CRISPR/Cas9-based genome editing for correction of dystrophin mutations that cause Duchenne muscular dystrophy. Nat Commun. 2015;6:6244. doi: 10.1038/ncomms7244. [PubMed: 25692716]. [PubMed Central: PMC4335351].

101. Matano M, Date S, Shimokawa M, Takano A, Fujii M, Ohta Y, et al. Modeling colorectal cancer using CRISPR-Cas9-mediated engineering of human intestinal organoids. Nat Med. 2015;21(3):256-62. doi: 10.1038/nm.3802. [PubMed: 25706875].

102. Grobarczyk B, Franco B, Hanon K, Malgrange B. Generation of isogenic human iPS cell line precisely corrected by genome editing using the CRISPR/Cas9 system. Stem Cell Rev Rep. 2015;11(5):774-87. doi: 10.1007/s12015-015-9600-1. [PubMed: 26059412].

103. Polstein LR, Gersbach CA. A light-inducible CRISPR-Cas9 system for control of endogenous gene activation. Nat Chem Biol. 2015;11(3):198200. doi: 10.1038/nchembio.1753. [PubMed: 25664691]. [PubMed Central: PMC4412021].

104. Ablain J, Durand EM, Yang S, Zhou Y, Zon LI. A CRISPR/Cas9 vector system for tissue-specific gene disruption in zebrafish. Dev Cell. 2015;32(6):756-64. doi: 10.1016/j.devcel.2015.01.032. [PubMed: 25752963]. [PubMed Central: PMC4379706].

105. Sander JD, Joung JK. CRISPR-Cas systems for editing, regulating and targeting genomes. Nat Biotechnol. 2014;32(4):347-55. doi: 10.1038/nbt.2842. [PubMed: 24584096]. [PubMed Central: PMC4022601].

106. Liao HK, Hatanaka F, Araoka T, Reddy P, Wu MZ, Sui Y, et al. In vivo target gene activation via CRISPR/Cas9-mediated trans-epigenetic modulation. Cell. 2017;171(7):1495-1507 e15. doi: 10.1016/j.cell.2017.10.025. 
[PubMed: 29224783]. [PubMed Central: PMC5732045].

107. Palermo G, Miao Y, Walker RC, Jinek M, McCammon JA. CRISPR-Cas9 conformational activation as elucidated from enhanced molecular simulations. Proc Natl Acad Sci USA. 2017;114(28):7260-5. doi: 10.1073/pnas.1707645114. [PubMed: 28652374]. [PubMed Central: PMC5514767].

108. Chang HK, Kim PH, Cho HM, Yum SY, Choi YJ, Son Y, et al. Inducible HGF-secreting human umbilical cord blood-derived MSCs produced via TALEN-mediated genome editing promoted angiogenesis. Mol Ther. 2016;24(9):1644-54. doi: 10.1038/mt.2016.120. [PubMed: 27434585]. [PubMed Central: PMC5113099].

109. Church GM, Elowitz MB, Smolke CD, Voigt CA, Weiss R. Realizing the potential of synthetic biology. Nat Rev Mol Cell Biol. 2014;15(4):289-94. doi: 10.1038/nrm3767. [PubMed: 24622617]

110. Baltimore D, Berg P, Botchan M, Carroll D, Charo RA, Church G, et al. Biotechnology. A prudent path forward for genomic engineering and germline gene modification. Science. 2015;348(6230):36-8. doi: 10.1126/science.aab1028. [PubMed: 25791083]. [PubMed Central: PMC4394183].

111. Ran FA, Hsu PD, Wright J, Agarwala V, Scott DA, Zhang F. Genome engineering using the CRISPR-Cas9 system. Nat Protoc. 2013;8(11):2281308. doi: 10.1038/nprot.2013.143. [PubMed: 24157548]. [PubMed Central: PMC3969860] 